paradigmas

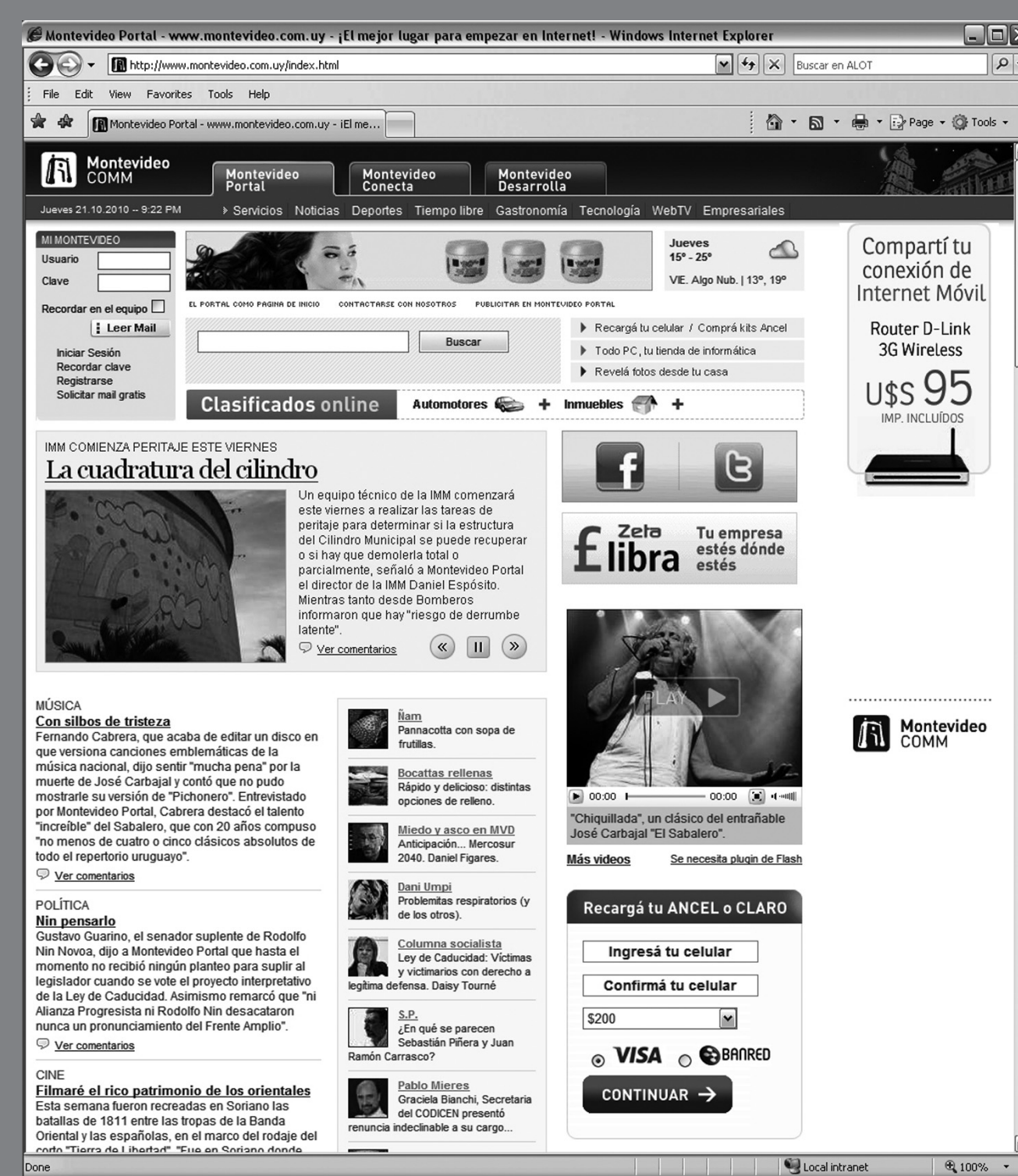




\section{Un portal con historia de innovación en Uruguay}

Por redacción de dixit

\section{El origen}

En 1991, tres ingenieros diseñaron un sitio, con el objetivo de difundir su trabajo vinculado al desarrollo del software y la conectividad. El espacio fue evolucionando a través del tiempo hasta convertirse hoy en Montevideo COMM, un portal con tres vertientes: Montevideo Conecta, Montevideo Desarrolla y Montevideo Portal. Montevideo Conecta ofrece servicios de Internet al segmento corporativo: hosting, datacenter, acceso a Internet de Banda Ancha, enlaces permanentes, redes de datos, voz sobre IP y redes privadas virtuales, además de ser proveedor de ADSL y otros servicios de acceso a Internet. Montevideo Desarrolla ofrece aplicaciones para Internet, con información dinámica e interactiva. Cuenta con un administrador de contenidos y generador de portales, que permite desarrollar programas de ventas por Internet, así como registrar y administrar las relaciones con los clientes. Montevideo Portal recibe 2.300.000 visitas mensuales; brinda información, contenidos y servicios a una comunidad de 300.000 usuarios registrados. Noticias, call center, información sobre tiempo libre, sorteos, alertas de mails y pronóstico del tiempo al celular, son algunos ejemplos.

\section{La versatilidad}

Montevideo COMM fue uno de los primeros proveedores de correo electrónico. En un inicio, el sitio tenía la entrada al correo y algunos servicios como horóscopo y envío de tarjetas de cumpleaños. Poco a poco fueron incorporando otros servicios, como las noticias. Rápidamente, los creadores advirtieron la necesidad de generar noticias propias. "Los servicios que tienen aceptación por parte de los usuarios se mantienen y los que no funcionan se dejan de hacer en el momento. Como el software es propio, tenemos mucho control sobre el clickeo. Vimos que las noticias funcionaban y avanzamos en eso", explicó a dixit María Noel Domínguez, editora de Montevideo Portal. Se realiza un monitoreo constante que permite identificar cuáles son los temas que generan mayor atención y también el grado de aceptación de las distintas secciones. "Subimos diez notas a las ocho de la mañana y a las once vemos cuál es la que está mejor, cuál es la que sigue en el día y la que no. Todo el tiempo nos vamos fijando en la evolución del clickeo y, si no funciona, se va sacando, a menos que sean cosas más duras”. Dos veces al día se envía una newsletter a los usuarios registrados y estas son instancias también para evaluar el interés de los lectores.

\section{El público}

Conectado, dinámico, internauta, demandante y con capacidad de poder comunicarse, son las principales características del público, que sabe que es escuchado a través de los canales diseñados para ello. Domínguez sostiene que "sería pecar de soberbios no escuchar a los usuarios, pero tampoco se puede escuchar a un usuario solo". Hay una comunicación directa con ellos a través de mails, foros, comentarios, Facebook, Twitter, además de las encuestas de satisfacción al
Organización::

Montevideo Comm Ciudad, año::

Montevideo, desde 1997 Rubro::

Portal de noticias, aplicaciones de Internet y servicios de hosting. 
cliente. Cuando a los usuarios no les gusta algo, lo dicen: "Los usuarios se sienten muy dueños del trabajo. Desde el inicio comenzamos con los foros y siempre estamos pensando en cómo aumentar la participación. Es una ventaja que el usuario se comunique con nosotros, esa es nuestra comunidad; no tenemos lectores solamente sino que es una comunidad", afirmó la editora del Portal.

\section{Participación y autorregulación}

“La autorregulación era una utopía en la que creí, pero la realidad luego demostró que no, que era imposible porque no había control, el usuario se registraba con muy pocos datos... y no fue un lugar de intercambio de opiniones y discusión sana. Así que empezamos a exigir más datos y a regular más la participación”.

Fidelizar y mantener activa esta comunidad de internautas implica un trabajo constante de búsqueda y actualización en los servicios y herramientas para que el público participe, se interese y disfrute: proveer correos, blogs, fotoblogs, enviar goles al correo y hacer sorteos de espectáculos. El seguimiento de un público fiel tiene sus ventajas económicas, reconoce Domínguez, aunque los usuarios no sean considerados clientes. Al momento de comercializar un producto, son más las personas que se enteran de las propuestas. Domínguez señala la importancia de generar y mantener usuarios con sentido de pertenencia respecto al portal: "Hay un valor inmaterial que es nuestra comunidad. Los usuarios son imperativos porque se sienten parte y eso está muy bien porque hace que vuelvan a leer, les da fidelidad. Esa comunidad permite que la empresa haga cosas. Ayuda al desarrollo comercial y da una permanencia de liderazgo al portal, porque la gente nos sigue leyendo".

\section{El equipo}

Ochenta personas trabajan en Montevideo Comm. El equipo está liderado por tres directores y un jefe por cada área: portal, diseño, desarrollo, ventas corporativas, ventas generales, soporte, mantenimiento y administración. Todos los lunes se realizan reuniones con la dirección para coordinar y actualizar la información acerca de lo que están realizando las diferentes áreas. La dirección marca prioridades y cada jefe de sección organiza y distribuye las tareas al equipo. Si bien las ideas surgen de forma espontánea, resulta importante organizarlas en función del trabajo.

"Cada uno de nosotros siempre tiene una idea para aportar; en verano apelamos a que surjan propuestas nuevas para ver de qué manera implementarlas en el año. Ahora cambiamos el diseño, pero lleva mucho tiempo y tiene que estar planificado. Organizamos un concurso de cuentos de Twitter que implica también planificación: definir el momento del año más apropiado, evaluar con qué otros productos irá a competir", explica la editora del Portal.

Actualmente, la producción periodística está a cargo de un equipo formado por diez comunicadores y una editora. El perfil de los periodistas ha variado en el tiempo y hoy se caracterizan por ser muy abiertos al cambio, tener capacidad para cubrir distintas secciones y manejar las herramientas tecnológicas. Este equipo trabaja en coordinación con el equipo de desarrollo de software y diseño para la creación de secciones. Están sustentados por el equipo de operaciones, que da seguridad y respaldo al usuario, monitoreando todo el tiempo los enlaces y servidores. El equipo de soporte además está escuchando al usuario cuando tiene problemas. Se agregan también los trabajadores del área administrativa y del call center.: 